\title{
Gendered Discourse of Pakistani Parents Regarding Professional Choices for their Children
}

\author{
Abdul Razaque Channa ${ }^{1}$, Khalid Hussain Channa ${ }^{2}$, \\ and Tayyaba Batool Tahir ${ }^{3}$
}

\begin{abstract}
Language plays a vital role in a person's identity construction. This research paper discusses how gender affects language and how responses vary from person to person while addressing the same issues. By drawing upon Cameron's Dominance Model, this research is aimed to present an analysis of variations in responses between male and female participants. It analyses how discourse differs when a group of female participants and a group of male participants talk on similar topics. This study is based on focused group interviews with a group of each gender on parental perceptions about the career of their children. Each group consists of 6-8 participants. Thematic analysis is used as an analytic technique to discover differences between male and female groups while sharing their perceptions. The paper found that gender discourse is shaped by socially dominated gendered norms which consequentially affect children's careers choice. This research implies that females' career options are based on the traditional conceptualization of career opportunities which don't empower them. They also face unequal opportunities to express their opinions or use their voice in daily life decisions and conversations freely.
\end{abstract}

Keywords: Gender; Language; Deficit Model; Cultural Difference Model; Dominance Model.

\section{Introduction}

Gender is a social construction and language plays a pivotal role in assigning and understanding the place of gender in society (Baxter, 2016; Francis, 1998). Many fields such as anthropology, sociology, communication, psychoanalysis, philosophy, education and economics attempt to see causes of gender differences. Discourse shape gender identity of individuals through communication exchange. And, communication requires language to convey the message from one individual to another in a society. Similarly, one person influences the other through the use of a language in our case male and female. Gender defines the actions, attitudes and behaviors of people. According to Butler, Gender is a "repeated stylization of the body (Judith, 1999)." Similarly, Cameron argues that gender is a culturally constructed male identity and female identity (Cameron, 2005). This paper is aimed to present

\footnotetext{
Department of Anthropology \& Archaeology, University of Sindh, Jamshoro, Pakistan. Government Sindh College, Hyderabad, Sindh, Pakistan.

Department of Sociology and Anthropology, Bahauddin Zakariya University, Multan, Pakistan.
}

*)Corresponding Author.

Email: razaque.channa@usindh.edu.pk 
an analysis of variations in responses between male and female participants about their likes and dislikes of the career choice. It explores the effects of gender on language, especially the differences in responding to the same topics. Mode of speech, even the words differ when two individuals talk to each other. Focused group discussions (FGDs) were conducted to understand male and female parents' views of parents about their children's careers. The thematic analysis was designed after the collection of the data. Themes were developed to understand the gender differences and male \& female preferences. Participant's views, themes, research methods, theoretical models, cultural expectations and analysis is presented in the following pages to understand the dynamics of language and gender.

\section{Overview of Language and Gender}

Understanding linguistic differences through gender is an important area of research for sociolinguists. Research studies are being conducted to analyze the relationship between gender and language. The concept of gender in language has changed over time \& space, politically and culturally (Sadiqi, 2003). According to Cameron, "a crude historical- typological account of feminist linguistic approaches since 1973 would probably distinguish between three models of language and gender (Cameron, 1995a)." These models are the deficit model, the cultural difference model and the dominance model.

\section{Deficit Model}

Deficit models suggest that females are judged to be weak speakers, especially at workplaces in a capitalist liberal economy (Block, 2002). Society gives limited space to female in socio-cultural and political space. Men's speech is generally accepted as a norm, unlike women's (Lakoff, 1973). In her verbal hygiene analysis, Cameron pointed out the pressure imposed on female members of society to monitor both the men's and their language and clean up their faulty language production accordingly (Cameron, 1995b). Similarly, keeping in view the male-dominated corporate sector, professional women face issues like glass ceiling when it comes to professional training and capacity building programs that otherwise may push them to enhance skills and learn strategies for future challenges and prospects.

According to Ellig and Morin, women think of themselves as weak and shy in a male-dominated society because they have been brought up since childhood to prefer to be less direct and more submissive (Ellig \& Morin, 2001). In this way, they traditionally believe that obedient women are always silent and those who contradict and speak out face trouble and lose opportunities. Therefore, women consider them deficit and follow modes of behavior laid down by men in the deficit model.

\subsection{Cultural Difference Model}

This model is different from the dominance model because the cultural model gives the impression that men and women are different and belong to separate 
classes. Still, they come from the same/equal cultures. Males and females are treated differently in the context of culture and religion due to having a different class (Block, 2002). Since they are different, they are socialized differently while sharing the same culture. Boys and girls are nurtured in different ways. They are taught to play with different toys. Girls are informed to stay at home whereas boys go out. The boy and the girl learn to interact and communicate while keeping the gender impression and nuances in mind. They acquire different communicative styles within the community they live (Davis \& Skilton-Sylvester, 2004). In a culturally different model, it is believed that men and women are different but equal: women's speech and communication style are not inferior to men's; rather, the relationship between the two is problematic at least in part because of the patriarchal structure of the society (Block, 2002).

\subsection{Dominance Model}

In this model, women are considered to act and talk in an ethnomethodological frame. This model is adopted by most researchers who think that men gain power over women in social interaction by means of interrupting and overlapping women's speech, using a high volume of words (Davis \& Skilton-Sylvester, 2004). According to Cameron, the dominance model challenges the foundations of socio-economic hierarchies in different societies worldwide. It is not individuals' ways of speaking but a complete social structure that has given men dominance over women.

\section{Research Methodology}

Qualitative data collection methods were used especially conducting Focus Group Discussions (FGDs) for this research (Bernard, 2017). Four focus group discussions were carried out over the topic of parents' views about their children's careers. A semi-structured interview protocol was prepared, and probes were made where required. This study was carried out in two public sector schools of Hyderabad, Sindh: Government Boys School and Government Girls School. Due to anonymity, the names of schools are not disclosed. Members of the Parent-Teacher Association (PTA) were involved. PTA's cooperation in connecting with the parents was instrumental in conducting the FGDs especially the female parents in Government Girls School. Since both the schools were located in Hyderabad's populated urban vicinity, the PTA and parents of the children were very cooperative. The researchers sought permission from the school administration to talk to parents and arrange a meeting with parents. Two focus group discussions were carried out with female participants and two with male participants. Two focus group discussions, i.e., one with male and one with female participants, were carried out in one public sector school and the other two in the other school. Two focus group discussions were carried out with female participants and two with male participants. 8 females and 6 males participated in each focus group discussion. A total of 28 informants participated in this study. Each focus 
group discussion lasted from 50-65 minutes. All the participants had various educational qualifications. The education of the respondents ranges from intermediate to Master of Philosophy. The participants of this study were diverse in terms of their occupation. All male participants were employed in public or private sector institutes and organizations. However, out of 16 only 9 female participants were working and 7 were household women. The working female participants were doing the job either in the education or health sectors. Health and Education sector is regarded as the suitable and desired profession for women in Pakistan because it is considered as a comfortable profession where the workers don't have to go from one place to another daily. Besides this, teaching profession is considered as a respectable job. The teacher becomes the torch bearer and spread the light through education among children or those who are unable to read and write. Similarly, nurses and female doctors are regarded as care giver or life saver who looks after their children when they are unwell. Women as caregiver role are envisioned as the most prestigious and rewarding job in the society because females involved into these professions are seen as mother.

The Focus Group Discussions (FGDs) were carried out through open discussion over the topic of 'views of parents about their children's career with the participant. Open ended questions with cross questions were asked in a very friendly but in a respectful way. The participants discussed their experiences of career and what in fact, influence them to decide about various professions and jobs. The data was recorded using a mobile phone recorder. The participants were informed of the purpose of the discussion and were taken into confidence. They were briefed about the research topic and why this research is conducted. Both privacy and confidentiality were assured and observed. This made them express themselves freely. Every participant introduced himself/herself with name, profession and number of children respectively in their groups. In order to comply with the research ethics of maintaining the anonymity of respondents, pseudonyms are used in this paper. The audio-recorded data collected from the focus group discussion was transcribed. The transcribed data were analyzed by tracing key themes such as 1. Career choice for male and female, 2. Career's relationship with gender and social status, 3. Tough jobs (fieldwork-based) and comfortable jobs (a fixed hour and fixed location), 4. Male as 'us' vs. female as 'other' and 5. Power to decide about the career of a male and female child. These themes were taken into account due to the existing normative practices in the society so to understand what factors lay when parents conceptualize gender and career. For example, career choice for male and female is dependent to the space and mobility. Parents welcome jobs that don't require an extensive physical mobility of a female. They like jobs which are either in the vicinity to their residential area or within their hometown. Also, there are certain stereotypes associated with the females which are frequently used in daily language such as 'Sinf-e-Nazuk' which present female as a weak gender, fragile and feminine. Jobs that require physical strength and physical movement are 
considered to be suitable for males. Jobs that don't require bodily strength or going from one place to another are suitable for females. People are conscious of the quotidian discourse which label parents as someone who go against the societal norm and allow their daughters to join any profession that require relocation and staying away from the family. Parents keep these daily discourses and decide about the career of their children. Similarly, it is a widespread notion in the Sindhi society that man is hierarchal head of the house and stays in home after the marriage. He looks after the family and strive to meet the needs of his house even if he does multiple job or shifts his home to the new location. In contrast, a girl leaves the parental home to stay with her husband and family after the marriage. The girl is considered as the 'other' who is temporary. Her permanent home is somewhere else. The above themes offer an insight into the parents' decisions about their children and what factors influence them. The researchers have given examples from the field which highlight the gender dynamics as envisioned by the parents.

\section{Analysis and Discussion}

\subsection{Thematic Analysis on views of female participants}

The female participants talked about general established trends in society. They generally spoke that there are certain professions, which are gender appropriate, and suit either males or females. The job of teaching or nursing is considered fit for females and it is socially acceptable. Whereas the tough, public dealing, business, army and other challenging jobs are associated with the male. Similarly, due to limited access to quality education and exposure, professional careers are confined to doctors, engineers, police, or teachers in rural areas. Asma said, "I think my son should be a good doctor but let's see." Fareeda said, "My husband wants our son to be an army officer and I think it is a good career choice." Asma said, "Daughters are guests. One day they have to go to their in-laws, so we should train them in domestic chores so they perform well in their new home." Raheela intercepted and shared her opinion, "We may give our daughters choices like we offer various career-related options to our sons. We may provide them similar opportunities to our daughters. The world has changed and we need to change our thinking." Sadia said, "My husband wants to educate our daughters as long as they wish." Sadia further said that "We live in a village but my son studies in a private academic academy at Hyderabad for an exam entry test preparation for engineering. We also sent our daughter to Hyderabad along with our son for an exam entry test preparation, but she could not stay there for long. She was homesick and returned back to us."

The participants opined that though the Sindhi society has set high respect for the daughters and the fathers love them more as compared to sons, but such affection loses its strength against the cultural barriers despite the encouragement by fathers. It is Deficit Model in which women are expected to work in a limited space. A girl is supposed to remain at home; it is considered that women place is home. If a boy is late at home, no explanation is required 
by parents. Asma said, "My daughter is interested in cooking instead of studying and I think one day it will help her in life." Fareeda said, "My soul becomes restless as long as my daughter is out of home for studies. It is insecurity outside because there are many men of different kinds. We have heard horrible news about the men's misbehavior with women. I do not feel the same for my son when he is out. He is man and he has many friends out there" Raheela seconded Fareeda by saying that we become concerned if our daughters get late from school. Asma said, "My husband is a very conservative and he asks me about our children. Our children are close to me and share everything if something wrong happens to them. I and my husband take decision about our children, but my husband words are final." Parents have authority to decide the career of their children. They set the choice and consider the child's intentions, interest existing family financial resources. Parents think of socially accepted values regarding professions before making any decision for their children. The girls usually select the job of teaching and nursing because it doesn't require mobility. In contrast, the boys opt for jobs with social privilege and social status no matter if the jobs demand challenging tasks and or staying away from family. The boys are given more space and career opportunities to avail themselves as compared to girls. Traditionally, a young boy is considered fit to deal in public spheres and live alone out of the home. On the other hand, the girls are not considered to perform well in challenging conditions. They are usually confined within homes and they are socialized to be submissive and take an interest in domestic affairs such as cooking, cleaning and looking after the family members. Some girls aspire to be a doctor or a teacher or learn home management skills.

\subsection{Thematic Analysis on views of male participants}

The participants were mostly teachers besides the one who was a clerk in a school of government in Sindh. Regarding the child's career, they said that it is up to 'child psychology and skills,' to determine the child's career. Parents said that they wanted to see their children either to be a doctor or an engineer because people respect these professionals. Parents cherish desires but their children execute them based on their skills. However, the boys are considered the future investment and family descendants and solely responsible for earning the family reputation and image. Akhtar said, "I want to see my son as a doctor and I prefer my daughter to be at home and learn household chores. He said, "Chokri parae aahe, chokro bhaandaaro aahe" [Author's translation: Girl leaves home after the marriage and stays with her husband's home whereas the boy is a moneybox].

The fathers shared that it is important to discipline the children. Parents should teach them social ethics and public responsibilities. In our society, boys are difficult to handle compared to girls. Girls don't argue and they don't require explanation. When girls are out of home, parents worry until they return safely, whereas boys handle the situation by themselves. Girls are regarded as an honor of the family and considered as "guests" in Sindhi culture 
because girls leave their parental home after the marriage and lives with a husband or with the husband's family. Bilal said, "We belong to the village and it is considered awkward to send our young daughters to city for education. We marry our daughters within our clan soon after she reaches to puberty. I have three daughters. They got primary education only and living a happy life with their husbands now." He said, "Aurat hik pasiree ji hadee aahe, sidhee kanda ta bhaji pawandi" [Author's translation: Woman is like a rib, if we try to straighten her, it will be broken]. Keeping in view the prevalent cultural traditions and customs set by their forefathers, the fathers wanted their daughters to remain within the homes, learn household chores, which would ultimately benefit women after their marriage. Naeem is a father of four daughters and five sons who said regarding his children's educational career, "I teach my daughters up to grade five (primary schooling) as they may be able to read and write." He further said, quoting his neighbor who educated his daughter up to intermediate. Soon after marrying, she visited local police station and reported against her husband. The police came and arrested her husband. She got a divorce later. Akhtar intercepted and said, "There is my distant friend who spent all her resources on her daughter's education. She became doctor but she refused to marry her cousin. She didn't listen to her father about the marriage proposal and refused him. Her father considers her behavior as an insulting because everyone among the relatives blames the father for educating her" Parents believe that higher education for girls make them disobedient and goes against the family values. Girls usually do not accept the conventional type of traditions.

Sons are given more space and opportunities to study and interact with their friends in the society; hence, the public spheres are made for them rather than girls. Deedar who participated in the FGD, said, "I want to make my son CSS officer. I provide him everything. I spend a lot of money on him. He will carry my name and will bring honor to our family. I also provided every facility to my daughter. She wants to be a lecturer."

The participants believed that the parents living in rural and urban areas think differently. The participants had also tried to associate one of the reasons for the backwardness of women with the missing facilities in rural areas where there has always been a lack of education, economic opportunities and protection issues. While drawing a visual picture of the rural life, participant discussed that rural dynamics are entirely different in terms of getting inspiration about career or becoming independent and self-made person. People talk about everything and everyone whatever happens in the town. There are not many examples of successful individuals (man or woman) who become someone without the support of their parents and parents' resources. In rural areas, it is typically men who have authority to decide about the education, career and marriage of their children.

The participants said that their daughters never show their interest either to get higher education or a job for themselves. Ideally, such submissive girls are accepted in families who never raise their voices against their rights. Hence, 
the girls are more compromising. Akhtar said, "Dhee Hujat na kandi aahe, putt hujat kando aahe" [Author's translation: Daughter does not ask for anything, son demands]. The daughters don't demand but the sons never hesitate to ask for things that he needs. Bilal intercepted that the daughters don't demand due to sharam ae hayaa [Author's translation: Shyness and bashfulness].

\subsection{Analysis of Language used by male and female participants}

Female participants used "may," "I think," "should," and "maybe." These types of sentences reveal that they were not decision-makers. Their ideas need further approval of someone who is the final decisionmaker at home. The female participants were not judgmental in their views and they lacked assertiveness. Whereas male participants were clear and confident in speaking about the future of their children because they have authority to decide. In this context, language and responses also vary due to the gender difference i.e., male or female. Ideas of male were supported by cultural and conventional sayings. Male participants were more vocal and imposing while talking about the future of their children. The sense of possession on their children life was vibrant in their conversation so much so that they considered deciding the course of life of their children.

\subsection{Analysis of body language of male and female participants}

The female participants used their only one hand while discussing. They didn't move while sitting on their chairs. They were very careful in their physical movement. They idealized only a few professions which were very commonly associated with the females in Sindhi Society. The had limited career options and were always conscious about their family and the societal expectation from a them as a female. They used each word carefully as if their talk needs further validation or acceptance, probably, from their father, brother, husband or mother or sister. While discussing in the FGDs, the women were not assertive, promising neither they gave any impression that they are sure that they can be 'engineer', 'doctor', 'police woman' or 'politician'. Movement of hands and eyes were different to what male participants when they were speaking during the FGDs. Female participants were very reserved in commenting on career choices and idealizing successful professional women. On the contrary male participants seemed confident and robust while discussing about the career of their children. They were active and many a times they gave examples from the society to justify what they are saying: sometimes approving and sometimes disapproving their friends. Their body language was vivacious. They used their both hands simultaneously and their sitting posture was relaxed. They did not stop for a while during discussion. They intercepted, opposed and participated sharing their experiences. Tone and pitch of voice was high. The pattern of intonation was full of confidence. The difference of male and female in their discussion is influenced by their 
cultural repertoire, norms and values. However, the way they participated in the discussion manifested the gendered aspect of the language.

\section{Conclusion}

Gender and language have an intrinsic relationship which not only manifest the cultural meanings but reflects the power dynamics within the society. Because gender and power work together in social relations (Foucault, 1980; Hall, 2001). This research paper concludes that language becomes gendered when powerful individuals use it as a tool to subjugate less powerful for the purpose to gain their objective. Likewise, use of language is never neutral or it doesn't have a gender fair face in the context of Sindhi society. Gender becomes visible when the language is used in daily discourse by parents for their children career. Similarly, power, language and gender have a relationship which becomes meaningful when the man speaks about women in a patriarchal structure of the society. Power is associated with language and gender which makes an individual dominant or subservient (Ball, 2013; Rabinow, 1984) in our case male is dominant and the female is subservient in the usage quotidian language use. The findings suggest that women think and see things from their own perspective, which is why women talk and interact in different way. A person's contribution to an ongoing discussion is determined not simply by utterance the person produces, but by the ways in which the utterance is received and interpreted by others in the conversation. Male and female participants epistemologically viewed the same world differently. Social status and expectation of society influence the parents in deciding the career pf their son and daughters. Respondents' replies provide an insight into the Sindhi society's constructing the gender of man and women. Dominant discourse associating man as breadwinner, head of household and decision maker whereas woman as an 'other' and leaves the home after marriage further strengthen the patriarchal structure of the society. Such subtle discourses become the means to subjugate women through cultural difference model, dominance model and deficit model.

\section{References}

Ball, S. J. (2013). Foucault and education: Disciplines and knowledge: London, Routledge.

Baxter, J. (2016). Positioning language and identity: poststructuralist perspectives. In The Routledge handbook of language and identity (pp. 60-75): Routledge.

Bernard, H. R. (2017). Research methods in anthropology: Qualitative and quantitative approaches: Rowman \& Littlefield.

Block, D. (2002). Language and gender and SLA. Quaderns de Filologia. Estudis Linguistics, 7, 49-73.

Cameron, D. (1995a). Rethinking language and gender studies: some issues for the 1990s. Language and gender: Interdisciplinary perspectives, 3144 . 
Cameron, D. (1995b). Verbal hygiene. In: London: Routledge.

Cameron, D. (2005). Language, gender, and sexuality: Current issues and new directions. Applied linguistics, 26(4), 482-502.

Davis, K. A., \& Skilton -Sylvester, E. (2004). Looking back, taking stock, moving forward: Investigating gender in TESOL. Tesol Quarterly, 38(3), 381-404.

Ellig, J. R., \& Morin, W. J. (2001). What every successful woman knows: 12 breakthrough strategies to get the power and ignite your career: McGraw-Hill Companies.

Foucault, M. (1980). Power/knowledge: Selected interviews and other writings, 1972-1977: Random House Digital, Inc.

Francis, B. (1998). Power plays: Primary school children's constructions of gender, power, and adult work.

Hall, S. (2001). Foucault: Power, knowledge and discourse. Discourse theory and practice: A reader, 72, 81.

Judith, B. (1999). Gender trouble: feminism and the subversion of identity. In: Routledge.

Lakoff, R. (1973). Language and woman's place. Language in Society, 2 (1), 45-79.

Rabinow, P. (1984). The Foucault Reader. New York: Pantheon.

Sadiqi, F. (2003). Women, gender, and language in Morocco (Vol. 1): Brill. 